\title{
Hepatitis B virus-related liver diseases: Identity and evidence-based control strategy
}

\author{
Mamaun Al Mahtab', Sheikh Mohammad Fazle Akbar² \\ ${ }^{1}$ Department of Hepatology, Bangabandhu Sheikh Mujib Medical University, Dhaka, Bangladesh, \\ ${ }^{2}$ Department of Medical Sciences, Toshiba General Hospital, Tokyo, J apan
}

Hepatitis B virus (HBV), a member of $\mathrm{H}$ epadnaviridae family, represents a small virus of about $3200 \mathrm{bp}$ and infects human and higher primates. Although the virus is hepatotrophic in nature, it has been detected in many organs and tissues including blood of infected human. HBV infection is universal in nature and about 2 billion people of the world have been infected with the HBV at some point of their life. Among them, considerable numbers of $\mathrm{HBV}$-infected subjects have developed protective antibody to HBV (antibody to hepatitis B surface antigen [anti-HBs]) and are immune from future HBV challenge. On the other hand, several million HBVinfected subjects express antibody to hepatitis B core antigen (anti-HBc) without expressing replication product of HBV (hepatitis B surface antigen [HBsAg]). However, these inactive HBV carriers may enter to active HBV replication cycle due to alteration of life style or several other causes. Finally, about 240 to 370 million people allow active $\mathrm{HBV}$ replication and express $\mathrm{HBs} \mathrm{Ag}$ and HBV DNA in the sera. Among these chronic HBV carriers, several millions develop chronic hepatitis B (CHB), liver cirrhosis (LC) and hepatocellular carcinoma (HCC). If these epidemiological evidences are compiled, it is evident that primary, mid-point and ultimately fate of HBV infection is not only diverse but also poorly understood. More importantly, the kinetics of HBV infection and liver-damaging properties and potentials of HBV could not be explained by HBVrelated factors. Neither the viral load (HBV concentrations) nor the expression levels of $\mathrm{HBV}$-related

Corresponding author: Dr. Mamaun Al Mahtab E-mail: shwapnil@agni.com

Received: 19-02-2016

Accepted: 23-03-2016

H ow to cite this article: Mahtab MA, Akbar SMF. Hepatitis $B$ virus-related liver diseases: Identity and evidence-based control strategy. J Gastrointest Infect, 2016; 6:1-2 antigens (HBsAg, HBeAg) or antibodies (ant-HBe, anti$\mathrm{HBc}$ ), nor HBV genotype or viral mutation could be accounted for genesis of protection, in active HBVcarrier state, chronic HBV-carriers, and pathogenesis of patients with CHB, LC and HCC (natural course of HBV infection). ${ }^{[1,2]}$

The liver damages induced in some HBV-infected patients seem to be inflicted by host immune system, the nature and property of which is yet to be completely clarified by future investigations. It seems that when an appropriate cellular and humoral immunity is induced after HBV infection that leads to development of protective immunity from future $\mathrm{HBV}$ challenge. However, if the host immunity is impaired or distorted in HBV-infected patients, the patients start to allow HBV replication and subsequently immune-mediated damages and destruction of hepatocytes and progression of hepatic fibrosis leading to pathogenesis of CHB, LC and possibly HCC. ${ }^{[3]}$ These observations have been supported by the fact that HBV is a noncytopathic virus and it is unable to induce direct damage and death of any hepatocyte or other tissues. This scenario is more complicated by the fact that there are various forms of HBV in infected human, such as replicating $\mathrm{HBV}$, covalently closed circular DNA (cccDNA) and extra-hepatic HBV DNA.

Under these realities, some new insights are required to manage patients with $\mathrm{CHB}, \mathrm{LC}$, and $\mathrm{HCC}$ because commercially-available antiviral drugs are capable of controlling only replicating HBV DNA, but not cccDNA. Their role on extra-hepatic HBV DNA is yet to be analyzed. At the same time, these antiviral drugs should be used for prolonged period or even for life and their long-term usage may be related to emergence of mutation and some of these may be life-threatening as well. Although a new and novel therapeutic approach for $\mathrm{CHB}$ may be restoration of host immunity in 
appropriate manner, the design and nature of therapeutic immunity in $\mathrm{CHB}$ patients is under investigation. It has been found that non-antigen specific immune modulators may not be a proper therapeutic choice for these patients. ${ }^{[4]}$ Rather, HBV antigen-specific immune therapy may be worthy and different designs of HBV antigen-specific immune therapies are on trial at clinical levels. ${ }^{[5,6]}$

$\mathrm{HBV}$, a terrorist virus of our time, needs to be properly dissected so that millions of $\mathrm{HBV}$-infected patients may be rescued from more time-consuming complications. The good information about HBV is the presence of a prophylactic vaccine, but its limitation should also be borne in mind. Thus, simultaneous development of more potent prophylactic vaccine and innovative therapies remain the challenge of our time to tackle HBV.

\section{REFERENCES}

1. Seeger C, Mason WS. Molecular biology of hepatitis B virus infection. Virology. 2015;479-80:672-86.

2. Hadziyannis SJ, Vassilopoulos D, Hadziyannis E. The natural course of chronic hepatitis $B$ virus infection and its management. Adv. Pharmacol 2013;67:247-91.

3. Maini MK, Boni C, Lee CK, Larrubia JR, Reignat S, Ogg GS, et al. The role of virus-specific CD8(+) cells in liver damage and viral control during persistent hepatitis B virus infection. J. Exp. Med. 2000;191:1269-80.

4. Sprengers D, Janssen HL. Immunomodulatory therapy for chronic hepatitis B virus infection. Fund. Clin. Pharmacol. 2005; 19:17-26.

5. Akbar SM, Al-Mahtab M, Khan MS. Non-antigen-specific and antigen-specific immune therapies for chronic hepatitis $B$ : evidences from laboratory benches and patient's bedsides. Expert Opin Biol Ther. 2013;13:1063-74.

6. Akbar SM, Al-Mahtab M, Jahan M, Yoshida O, Hiasa Y. Novel insights into immunotherapy for hepatitis B patients. Expert Rev Gastroenterol Hepatol. 2016;10:267-76. 